"This is the pre-peer reviewed version of the following article: Formation of mixed bondangle linkages in zinc boromolybdate glasses, which has been published in final form at DOI:10.1111/jace.14233. This article may be used for non-commercial purposes in accordance with Wiley Terms and Conditions for Self-Archiving."

\title{
Formation of mixed bond-angle linkages in zinc boromolybdate glasses
}

\author{
Margit Fabian ${ }^{1,2^{*}}$, Erzsebet $\mathrm{Svab}^{2}$ \\ ${ }^{1}$ Centre for Energy Research, Budapest 1121, Hungary \\ ${ }^{2}$ Wigner Research Centre for Physics, Budapest 1121, Hungary
}

\begin{abstract}
The short and medium range structure of glassy $\mathrm{MoO}_{3}-\mathrm{ZnO}-\mathrm{B}_{2} \mathrm{O}_{3}$ has been studied by neutron diffraction and reverse Monte Carlo simulation. The partial atomic pair correlation functions and coordination numbers are presented, not yet reported for this system. We have established that the first neighbor distances do not depend on concentration within limit of error, the actual values are $r_{B-O}=1.38 \AA, r_{M o-O}=1.72 \AA$ and $r_{Z n-O}=1.97 \AA$. It is found that $\mathrm{ZnO}$ takes part in the glassy structure as network former, as $\mathrm{ZnO}_{4}$ tetrahedral are linked both to $\mathrm{MoO}_{4}$ and to $\mathrm{BO}_{3}$ and $\mathrm{BO}_{4}$ groups. It is revealed that $\mathrm{BO}_{4} / \mathrm{BO}_{3}$ increases with increasing $\mathrm{B}_{2} \mathrm{O}_{3}$ content. We have found that only small amount of boroxol ring is present, $\mathrm{BO}_{3}$ and $\mathrm{BO}_{4}$ groups are organized into superstructure units, and a small part is in isolated $\mathrm{BO}_{3}$ triangles. The $\mathrm{BO}_{3}$ and $\mathrm{BO}_{4}$ units are linked to $\mathrm{MoO}_{4}$ or $\mathrm{ZnO}_{4}$ forming mixed ${ }^{[4]}$ Mo-O- $-{ }^{[3]} \mathrm{B},{ }^{[4]} \mathrm{Mo}-\mathrm{O}-{ }^{[4]} \mathrm{B},{ }^{[4]}$ Mo-O-O${ }^{[4]} \mathrm{Zn},{ }^{[3]} \mathrm{B}-\mathrm{O}-{ }^{[4]} \mathrm{Zn},{ }^{[4]} \mathrm{B}-\mathrm{O}-{ }^{[4]} \mathrm{Zn}$ bond-linkages.
\end{abstract}

\section{Introduction}

Zinc boromolybdate materials are known as low melting dielectric materials and they have high potential in several applications, due to their stable and unique structure with favourable optical properties [ 1 and references therein]. The glass formation tendency of $\mathrm{MoO}_{3}-\mathrm{ZnO}-\mathrm{B}_{2} \mathrm{O}_{3}$ and of several other similar compositions has been explored and the optical spectroscopic features have been analyzed by Dimitriev et al. [1-8]. The structure characterization is challenging, as far as this system contains the conditional network former $\mathrm{MoO}_{3}$ and the traditional network former $\mathrm{B}_{2} \mathrm{O}_{3}$. For $\mathrm{B}_{2} \mathrm{O}_{3}-$ based glasses it is widely accepted that the network consists of $\mathrm{BO}_{3}$ and $\mathrm{BO}_{4}$ groups [9-17], however, the question often arises concerning the relative amount of the trigonal and tetrahedral units. The basic network former units in $\mathrm{MoO}_{3}$-based glasses are $\mathrm{MoO}_{4}$ tetrahedral, however, for systems with high concentration (> $80 \mathrm{~mol} \%$ ) both $\mathrm{MoO}_{4}$ and $\mathrm{MoO}_{6}$ units are present [3, 18-20]. Several studies deal with $\mathrm{ZnO}$ containing glassy systems, concerning the role of $\mathrm{Zn}^{2+}$ cations, which may act as modifier if its fraction is low or network former in case of relatively high content of $\mathrm{ZnO}$ [1, 21-25]. The glassy $\mathrm{xMoO}_{3}-50 \mathrm{ZnO}-(50-\mathrm{x}) \mathrm{B}_{2} \mathrm{O}_{3}(\mathrm{x}=10,20,30 \mathrm{~mol} \%)$ have been prepared and thoroughly investigated using various optical spectroscopic methods and DTA [1]. Concerning the structural characteristics it was found, that the molybdenum-based glasses contain mainly $\mathrm{Mo}^{6+}$ ions and a small amount of $\mathrm{Mo}^{5+}$ ions might be present. It was found, that the coordination state of $\mathrm{Mo}^{6+}$ ions is mainly $\left(\mathrm{MoO}_{4}\right)^{2-}$ tetrahedral units, and formation of diborate, triborate and tetraborate groups, which contain $\mathrm{BO}_{3}$ triangles and $\mathrm{BO}_{4}$ tetrahedra was also suggested.

In order get deeper insight into the network structure, including the inter-atomic distances and coordination distributions, we have undertaken neutron diffraction study combined with reverse Monte Carlo (RMC) modeling [26] on the same system. Our interest is mainly focused on the

\footnotetext{
* Corresponding author email: fabian.margit@energia.mta.hu
} 
characterization of the network former structural units and their bond-linkages forming the mediumrange order. Especially interesting question is the role of $\mathrm{ZnO}$, whether it acts as modifier or network former, not yet investigated for this system, as far as we know.

For the qualitative characterization of the glassy state Transmission Electron Microscopy (TEM) has been performed and Nuclear Magnetic Resonance (NMR) spectroscopy was applied to get complementary information on the boron environment.

\section{Experimental}

\subsection{Sample preparation}

The amorphous $\mathrm{xMoO}_{3}-50 \mathrm{ZnO}-(50-\mathrm{x}) \mathrm{B}_{2} \mathrm{O}_{3}, \mathrm{x}=10,20,30 \mathrm{~mol} \%$ samples have been prepared by $\mathrm{L}$. Alexandrov [1]. Commercial powders of reagent grade $\mathrm{MoO}_{3}, \mathrm{ZnO}$ and $\mathrm{B}_{2} \mathrm{O}_{3}$ were used as starting materials and were mixed in an alumina mortar. For this study $\mathrm{B}_{2} \mathrm{O}_{3}$ was isotopically enriched in ${ }^{11} \mathrm{~B}-$ isotope (99.6\%) in order to reduce the influence of the high neutron absorption of ${ }^{10} \mathrm{~B}$-isotope present in natural boron. For the NMR experiment also ${ }^{11} \mathrm{~B}$-isotope is needed to get good NMR signals. The homogenous oxide materials were melted at $1200-1250^{\circ} \mathrm{C}$ in platinum crucible. The glasses were obtained by pouring the melts onto an iron plate and by pressing with another iron plate, for more details see ref [1].

\subsection{Transmission electron microscopy}

Transmission electron microscopy (TEM) measurements have been carried out with a JEM-ARM 200F analytical electron microscope installed at the National Institute of Materials Physics, Bucharest [27]. Images were recorded at magnifications between 30 000-1 200000.

\subsection{Nuclear Magnetic Resonance measurements}

Nuclear Magnetic Resonance (NMR) experiments have been performed with an NMR MAGIC spectrometer operating at $600 \mathrm{MHz}$ installed in the Slovenian NMR Centre [28].

\subsection{Neutron diffraction experiments}

Neutron diffraction (ND) experiments were performed on the PSD diffractometer $\left(\lambda_{0}=1.068 \AA\right.$ ) [29] at the 10 MW Budapest research reactor in the momentum transfer range $Q=0.5-10$ $\AA^{-1}$ using the data for preliminary data analysis. The 7C2 diffractometer at the LLB-CEA-Saclay $\left(\lambda_{0}=\right.$ $0.726 \AA$ ) [30] was used in a broader $Q$-range up to $16 \AA^{-1}$. The powder specimens of about 3-4 g/each were filled in thin walled cylindrical vanadium sample holder of $8 \mathrm{~mm}$ and $6 \mathrm{~mm}$ diameter, respectively. Data were corrected for detector efficiency, background scattering and absorption effects. The total structure factor, $S(Q)$ was calculated by local software packages.

\section{Experimental results}

\subsection{Transmission Electron Microscopy analysis}

The homogeneity of the glasses was controlled by TEM imaging. According to the TEM observations, no crystallization or phase separation was detected for the studied samples, as illustrated in Figure 1.
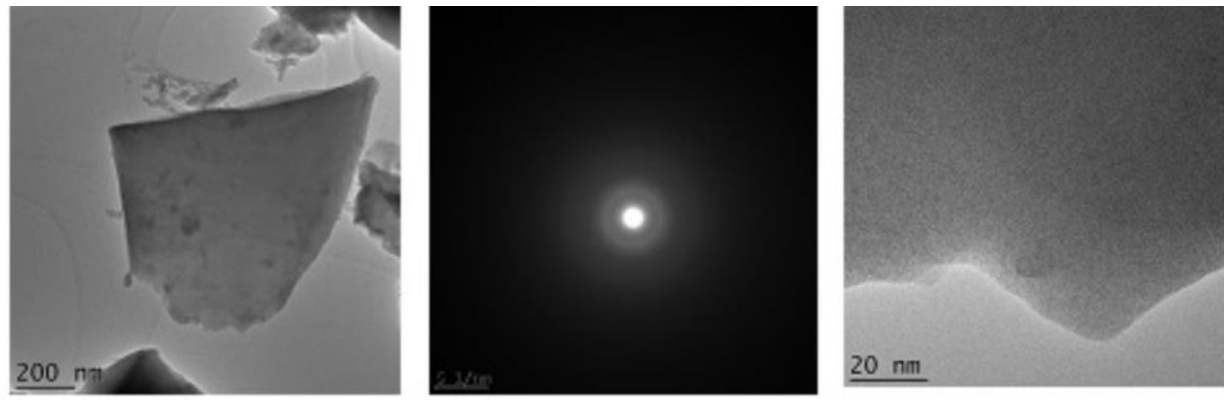

Figure 1. TEM images of $30 \mathrm{MoO}_{3}-50 \mathrm{ZnO}-20 \mathrm{~B}_{2} \mathrm{O}_{3}$ glassy sample. 


\subsection{Nuclear Magnetic Resonance results}

Figure 2 displays the experimental ${ }^{11} \mathrm{~B}$ NMR spectra. Two characteristic distributions have been detected: the first one at $1.72 \mathrm{ppm}$ peak position and a broad distribution between 7-20 ppm. Based on the literature (see Figure 1 in [16] and [17]) they are related to ${ }^{[4]} \mathrm{B}\left(\mathrm{BO}_{4}\right)$ and ${ }^{[3]} \mathrm{B}\left(\mathrm{BO}_{3}\right)$ structural units, as indicated in Figure 2. The peak intensities show slight, but significant concentration dependence. The intensity of the ${ }^{[3]} \mathrm{B}$ peak increases with decreasing boron content, while the ${ }^{[4]} \mathrm{B}$ peak decreases. The coordination numbers were calculated simple by integrating the area under these two distributions. The average B-O coordination numbers are 3.26, 3.24 and 3.21 atoms for the 40, 30 and $20 \mathrm{~mol} \% \mathrm{~B}_{2} \mathrm{O}_{3}$ content samples, respectively. The maximal change is only $\sim 1.5 \%$, but NMR is a highly sensitive method for the investigation of first neighbor oxygen coordination of ${ }^{11} \mathrm{~B}$-isotope. The ${ }^{[3]} \mathrm{B}$ peak is obviously a double peak with peak positions at 15.3 and $13.3 \mathrm{ppm}$, indicating two types of symmetry positions. Detailed analysis of the NMR experiment is underway, and will be published elsewhere.

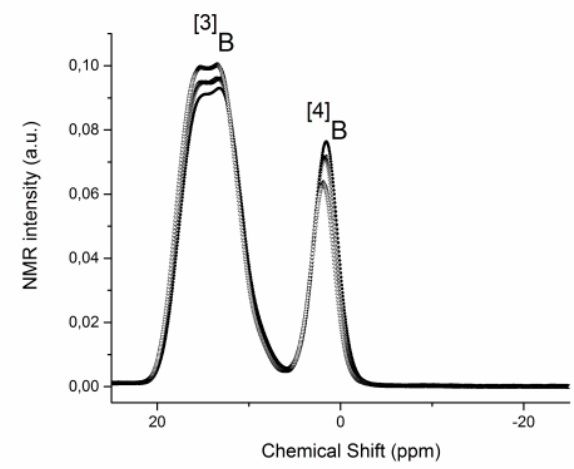

Figure 2. ${ }^{11} \mathrm{~B}$ NMR spectra of zinc boromolybdate glasses: $10 \mathrm{MoO}_{3}-50 \mathrm{ZnO}-40 \mathrm{~B}_{2} \mathrm{O}_{3}$ (dots), $20 \mathrm{MoO}_{3}-50 \mathrm{ZnO}-30 \mathrm{~B}_{2} \mathrm{O}_{3}$ (cross) and $30 \mathrm{MoO}_{3}-50 \mathrm{ZnO}-20 \mathrm{~B}_{2} \mathrm{O}_{3}$ (triangle).

\subsection{Neutron diffraction results}

Figure 3 presents the total structure factor, $S(Q)$ for the investigated zinc boromolybdate glasses. The results of the reverse Monte Carlo model calculation are also drawn in the same figure; they will be discussed later, in Section 4.

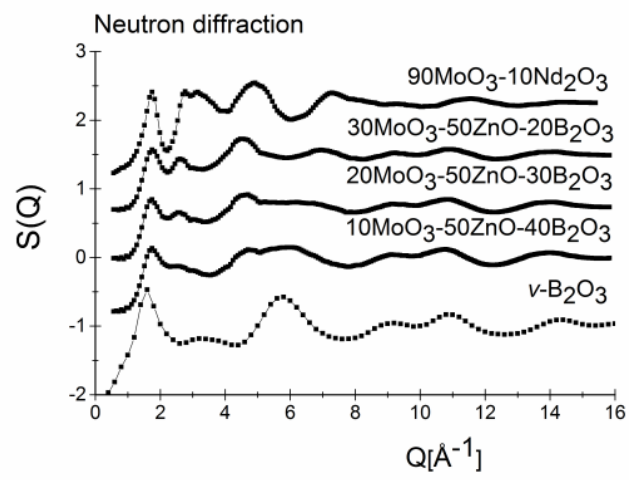

Figure 3. Neutron diffraction structure factor, $S(Q)$ of ternary zinc boromolybdate samples. The binary $v-\mathrm{B}_{2} \mathrm{O}_{3}[13]$ and $90 \mathrm{MoO}_{3}-10 \mathrm{Nd}_{2} \mathrm{O}_{3}$ [18] glasses are also displayed to help the interpretation of the observed chages: experimental data (marks) and RMC simulation solid line (The curves are shifted vertically for clarity).

Significant concentration dependence may be observed. The most striking features are the decrease of the peak intensities at $\sim 2.5, \sim 4.5$ and $\sim 7 \AA^{-1}$, and the increase of the peak intensity at around $6 \AA^{-1}$ 
with decrease of $\mathrm{MoO}_{3} / \mathrm{B}_{2} \mathrm{O}_{3}$ fraction (see from top to down). The actual peak positions are also shifted. In order to find support for the interpretation, we have displayed the $S(Q)$ data for the binary $v-\mathrm{B}_{2} \mathrm{O}_{3}$ [13] and $90 \mathrm{MoO}_{3}-10 \mathrm{Nd}_{2} \mathrm{O}_{3}$ [18], as they are the constituent network formers of the investigated ternary system. The basic tendency of the concentration dependence may be related to the characteristic features of the binary glasses, like the presence of the characteristic large peak at $5.8 \AA^{-1}$ in the $S(Q)$ of $v-\mathrm{B}_{2} \mathrm{O}_{3}$ or the characteristic peak at 4.9 and $7.3 \AA^{-1}$ for $90 \mathrm{MoO}_{3}-10 \mathrm{Nd}_{2} \mathrm{O}_{3}$ glass. It can be established, however, that the $S(Q)$ curves of the presently investigated ternary system are far not the weighted sum of the corresponding binary systems, which predicts a continuous network instead of separation of the two glassy networks. Due to the continuous change of the characteristic features of the $S(Q)$ pattern, the basic atomic scale characteristic features are expected to be preserved, while the main question is, how these units are connected to each other.

The characteristic features of the ternary glasses may be interpreted taking into consideration the different weighting factors, $w_{i j}$ of the partial structure factors, $S_{i j}(Q)$ contributing to the total $S(Q)$. In this work the following formalism is used:

$$
\begin{aligned}
& S(Q)=\sum_{i, j}^{k} w_{i j} S_{i j}(Q), \\
& w_{i j}=\frac{c_{i} c_{j} b_{i} b_{j}}{\left[\sum_{i, j}^{k} c_{i} b_{j}\right]^{2}},
\end{aligned}
$$

where $c_{i}, c_{j}$ are the molar fractions of the components, $b_{i}, b_{j}$ the coherent neutron scattering amplitude [31] and $k$ is the number of elements in the sample. The actual $w_{i j}$ values for the investigated ternary samples are tabulated in Table 1.

Table 1. Weighting factors, $w_{i j}(\%)$ of the partial structure factors, $S_{i j}(Q)$ and atomic pair-correlation

\begin{tabular}{|c|c|c|c|c|c|c|c|c|c|c|}
\hline \multirow{3}{*}{ Sample } & \multicolumn{10}{|c|}{ Weighting factors, $w_{\mathrm{ij}}(\%)$} \\
\hline & \multicolumn{10}{|c|}{ Atom pairs } \\
\hline & Mo-O & Zn-O & B-O & O-O & Mo-Mo & Mo-Zn & Mo-B & $\mathbf{Z n}-\mathbf{Z n}$ & Zn-B & B-B \\
\hline $10 \mathrm{MoO}_{3}-50 \mathrm{ZnO}-40 \mathrm{~B}_{2} \mathrm{O}_{3}$ & 3.74 & 15.80 & 29.54 & 32.22 & 0.10 & 0.91 & 1.72 & 1.94 & 7.25 & 6.78 \\
\hline $20 \mathrm{MoO}_{3}-50 \mathrm{ZnO}-30 \mathrm{~B}_{2} \mathrm{O}_{3}$ & 7.95 & 16.90 & 23.63 & 34.42 & 0.45 & 1.96 & 2.74 & 2.08 & 5.81 & 4.06 \\
\hline $30 \mathrm{MoO}_{3}-50 \mathrm{ZnO}-20 \mathrm{~B}_{2} \mathrm{O}_{3}$ & 12.82 & 18.00 & 16.88 & 36.84 & 1.11 & 3.14 & 2.94 & 2.20 & 4.13 & 1.94 \\
\hline
\end{tabular}
functions, $g_{i j}(r)$.

In order to get qualitative and some quantitative information for the local structure we have calculated the total atomic distribution function, $G(r)$ by sine-Fourier transformation as follows:

$$
G(r)=\frac{2}{\pi} \int_{o}^{Q_{\max }} Q[S(Q)-1] \sin Q r d Q
$$

where $Q_{\max }$ is the upper integration limit.

Figure 4 displays the $G(r)$ functions of the investigated zinc boromolybdate glasses, and also for the binary systems, with the aim to find the contribution of the actual atom pairs.

Vertical arrow lines indicate the atom pair positions, which were possible to identify. These are the BO distribution with peak position at $1.38 \AA$, which appears separately from the other distributions, as its value is significantly lower. Mo-O and $\mathrm{Zn}-\mathrm{O}$ distributions overlap with each other, centered at 1.75-1.95 ^̊. 


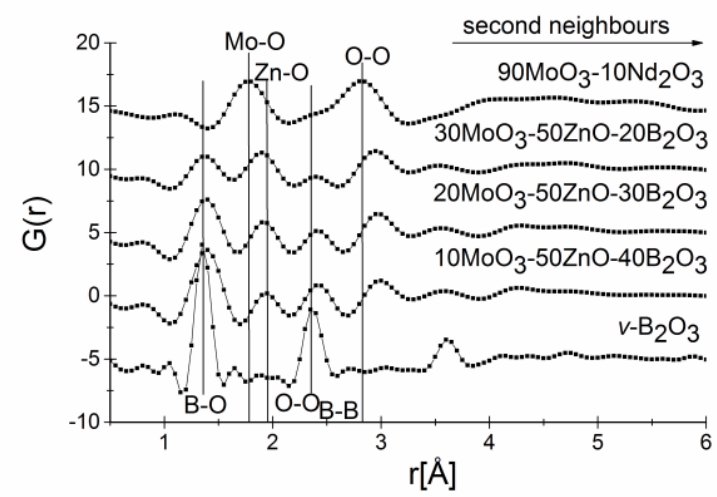

Figure 4. Total distribution functions, $G(r)$ calculated by eq. 3 (see text) from $S(Q)$ presented in Figure 3. (The curves are shifted vertically for clarity).

Note, that the weight of $G_{Z n-O}(r)$ is significantly higher than that for $G_{M o-O}(r)$ in the $10 \mathrm{MoO}_{3}-50 \mathrm{ZnO}$ $40 \mathrm{~B}_{2} \mathrm{O}_{3}$ sample (see Table 1), therefore it is possible to identify. The peak at $2.4 \AA$ relates mainly to the $G_{O-o}(r)$, which is a characteristic distance for the $\mathrm{BO}_{3}$ units and overlaps with $G_{B-B}(r)$ [13]. The peak at $\sim 2.8 \AA$ is related to O-O distance characteristic for Mo-centered oxygen neighborhoods [18]. For higher $r$-values the various atomic distributions overlap with each other, the only small peak at

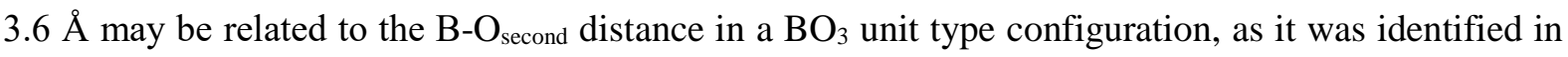
$v$ - $\mathrm{B}_{2} \mathrm{O}_{3}$ [13], which is used as a reference sample to analyze the ternary compositions. All these atomic distance values present valuable new information; furthermore, they serve as input parameters for the starting atomic configuration for the RMC modeling.

\section{Reverse Monte Carlo modeling}

\subsection{RMC simulation details}

The neutron diffraction experimental $S(Q)$ data have been simulated by the RMC method [26], which is a widely used effective tool to model disordered structures. The RMC minimizes the squared difference between the experimental $S(Q)$ and the calculated one from a 3-dimensional atomic configuration. The RMC algorithm calculates the one-dimensional partial atomic pair correlation functions $g_{i j}(r)$, and they are inverse Fourier transformed to calculate the partial structure factors, $S_{i j}(Q)$ :

$$
S_{i j}(Q)=1+\frac{4 \pi \rho_{0}}{Q} \int_{0}^{r_{\max }} r\left[g_{i j}(r)-1\right] \sin Q r d r,
$$

where $r_{\max }$ is the half edge-length of the simulation box. The atomic configuration of this computer calculation is modified by moving the atoms randomly until the calculated $S(Q)$ (see eqs.(1-4)) agrees with the experimental data within the experimental error.

In this study we have used the software package RMC++ developed by Pusztai et al. [32]. For the RMC starting model a random atomic configuration was built up with a simulation box containing 10 000 atoms with density data $0.087,0.081$ and 0.076 atoms $\cdot \AA^{-3}[1,33]$ and half-box values $r_{\max }=24.30$ $\AA$, $24.90 \AA$ and $25.43 \AA$ for the $10 \mathrm{MoO}_{3}-50 \mathrm{ZnO}-40 \mathrm{~B}_{2} \mathrm{O}_{3}, 20 \mathrm{MoO}_{3}-50 \mathrm{ZnO}-30 \mathrm{~B}_{2} \mathrm{O}_{3}$ and $30 \mathrm{MoO}_{3}-$ $50 \mathrm{ZnO}-20 \mathrm{~B}_{2} \mathrm{O}_{3}$ samples, respectively. In the RMC simulation procedure constraints have been used for the minimum interatomic distances between atom pairs (cut-off distances) to avoid unreasonable atom contacts. The starting cut-off distances have been taken from the experimental $G(r)$ function (see Figure 4) as discussed in Section 3.3. and from our previous study [18]. Several RMC runs have been performed by modifying slightly the cut-off distances in the way, that the results of each run have been carefully checked to obtain reliable data for each $g_{i j}(r)$ and coordination number distributions. For each sample about twenty RMC configurations were obtained with more than 2200000 accepted moves of atoms. 
The convergence of the RMC calculation was good and the final $S(Q)$ matched very well the experimental structure factor as it is shown in Figure 3. The actual set of cut-off distances used in the final RMC run was the following: B-O 1.15 $\AA$, Mo-O 1.6 $\AA$, Zn-O 1.9 $\AA$, O-O 2.3 $\AA$, B-B $2.5 \AA$, ZnB $2.7 \AA$, Mo-Zn $2.8 \AA$, Zn-Zn $2.9 \AA$, Mo-B 3.0 Å and Mo-Mo $3.1 \AA$.

4.2. $R M C$ results

From the RMC simulation several first and second neighbor partial atomic pair-correlation functions, $g_{i j}(r)$ and coordination number distributions, $C N_{i j}$ have been revealed with a fairly good stability and statistics. Figure 5 presents $g_{B-O}(r), g_{M o-O}(r), g_{Z n-O}(r)$ and $g_{O-O}(r)$ partial correlation functions for the different concentrations.
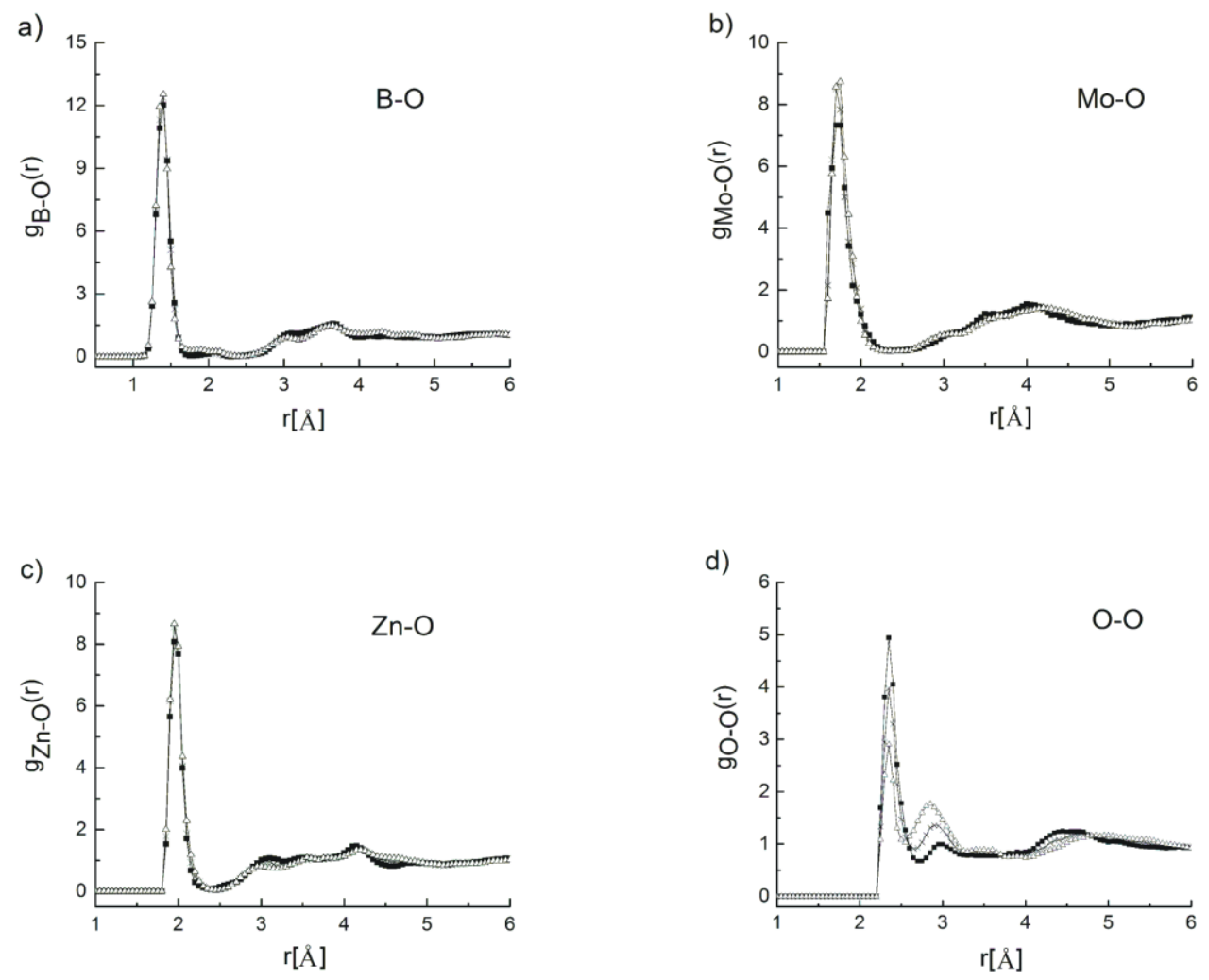

Figure 5. Partial pair distribution functions for $10 \mathrm{MoO}_{3}-50 \mathrm{ZnO}-40 \mathrm{~B}_{2} \mathrm{O}_{3}$ (square), $20 \mathrm{MoO}_{3}-50 \mathrm{ZnO}-$ $30 \mathrm{~B}_{2} \mathrm{O}_{3}$ (cross) and $30 \mathrm{MoO}_{3}-50 \mathrm{ZnO}-20 \mathrm{~B}_{2} \mathrm{O}_{3}$ (triangle) glasses.

The first neighbor distances were calculated by Gaussian-fit (a)-(c) with a relative small error, as they are tabulated in Table 2.

Table 2. First and second neighbour distances, $r_{\mathrm{ij}}(\AA)$ for the different atom pairs. The actual error is indicated in bracket $(\AA)$, as estimated from the data analyses of different RMC runs.

\begin{tabular}{|c|c|c|c|c|c|c|c|c|c|c|}
\hline \multirow[b]{3}{*}{ Sample } & \multicolumn{10}{|c|}{ Interatomic distances, $\boldsymbol{r}_{\mathrm{ij}}(\AA ̊)$} \\
\hline & \multicolumn{10}{|c|}{ Atom pairs } \\
\hline & $\begin{array}{c}\text { B-O } \\
( \pm 0.01)\end{array}$ & $\begin{array}{c}\text { Mo-O } \\
( \pm 0.01)\end{array}$ & $\begin{array}{c}\text { Zn-O } \\
( \pm 0.01)\end{array}$ & $\begin{array}{c}\mathbf{O - O} \\
( \pm 0.02)\end{array}$ & $\begin{array}{c}\text { B-B } \\
( \pm 0.05)\end{array}$ & $\begin{array}{c}\text { B-Zn } \\
( \pm 0.05)\end{array}$ & $\begin{array}{l}\text { Mo-Zn } \\
( \pm 0.05)\end{array}$ & $\begin{array}{c}\mathbf{Z n}-\mathbf{Z n} \\
( \pm 0.05)\end{array}$ & $\begin{array}{c}\text { Mo-B } \\
( \pm 0.05)\end{array}$ & $\begin{array}{c}\text { Mo-Mo } \\
( \pm 0.05)\end{array}$ \\
\hline $10 \mathrm{MoO}_{3}-50 \mathrm{ZnO}-40 \mathrm{~B}_{2} \mathrm{O}_{3}$ & 1.39 & 1.72 & 1.97 & $2.35 / 2.95$ & 2.60 & 2.85 & 2.90 & 3.05 & 3.10 & 3.15 \\
\hline $20 \mathrm{MoO}_{3}-50 \mathrm{ZnO}-30 \mathrm{~B}_{2} \mathrm{O}_{3}$ & 1.39 & 1.72 & 1.97 & $2.35 / 2.95$ & 2.60 & 2.85 & 2.90 & 3.05 & 3.10 & 3.20 \\
\hline $30 \mathrm{MoO}_{3}-50 \mathrm{ZnO}-20 \mathrm{~B}_{2} \mathrm{O}_{3}$ & 1.38 & 1.74 & 1.97 & $2.35 / 2.85$ & 2.70 & 2.84 & 2.90 & 3.06 & 3.10 & 3.20 \\
\hline
\end{tabular}

The B-O first neighbor distance shows slight concentration dependence, it changes from $1.38 \AA$ to $1.39 \AA$ with increasing boron content, which is in good agreement with our direct experimental observation obtained from the total distribution function, $G(r)$ (see Figure 4) and with our previous result reported for MoNdB-oxide glass $\left(r_{B-O}=1.40 \AA\right.$ [18]). The Mo-O distance shows a slight decrease 
from $1.74 \AA$ to $1.72 \AA$ with decrease of molybdenum content, the actual value is in accordance with other studies containing $\mathrm{MoO}_{3}\left(r_{M o-O}=1.75 \AA\right.$ [18], $1.77 \AA$ [34], 1.76-1.78 $\AA$ [35]). The Zn-O distance appears at significantly higher value, at $1.97 \AA$ for all three investigated samples. This value is in good agreement with the results obtained for other glasses with $\mathrm{ZnO}\left(r_{Z n-O}=1.93-1.95 \AA\right.$ [23], 1.83 $1.91 \AA[25], 1.94-1.97 \AA[36], 1.96 \AA$ [37]). The O-O correlation functions consist of double peak with characteristic distances at $2.35 \AA$ and at 2.85-2.98 $\AA$, the actual value of the second sub-peak depends on $\mathrm{MoO}_{3} / \mathrm{B}_{2} \mathrm{O}_{3}$ fraction. The intensity of both O-O "sub-peaks" depends on concentration. It is remarkable, that with increasing boron content the intensity of the first peak increases, while the intensity of the second one increases with the increase of Mo-content. This observation suggests that the first sub-peak originates mainly from the $\mathrm{O}-\mathrm{O}$ distance formed by the boron-oxygen units, with a similar value as it was found in $v-\mathrm{B}_{2} \mathrm{O}_{3}\left(r_{o-O}=2.38 \AA\right.$ [13] $)$ and in several alkali diborate glasses $\left(r_{0-O}=2.37-2.39 \AA[12\right.$ and therein]). The O-O second sub-peak is supposed to originate from molybdenum-oxygen units [18], however, the shift of the position to higher $r$-values suggests that it contains contribution from the zinc-oxygen distribution, as well.

The oxygen coordination distributions are shown in Figure 6. For B-O distributions both 3- and 4-fold coordinated oxygen surroundings have been revealed, and a small number $(<5 \%)$ of 2 oxygen neighbors, the latter is supposed to be an artificial effect of the RMC model calculation. The ratio of $\mathrm{BO}_{3}$ and $\mathrm{BO}_{4}$ units shows concentration dependence on $\mathrm{B}_{2} \mathrm{O}_{3}$ content.
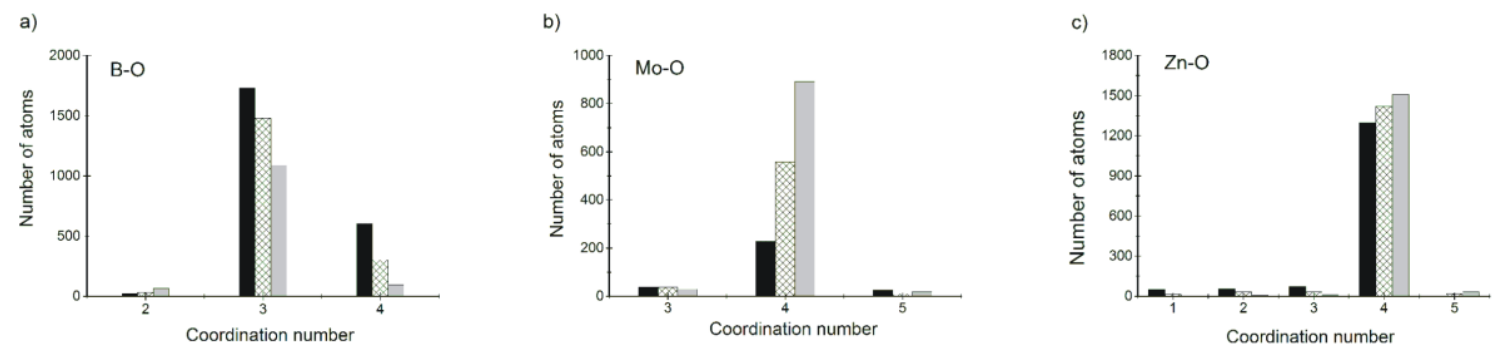

Figure 6. Oxygen coordination distributions: a) B-O, b) Mo-O, c) $\mathrm{Zn}-\mathrm{O}$ where $10 \mathrm{MoO}_{3}-50 \mathrm{ZnO}-$ $40 \mathrm{~B}_{2} \mathrm{O}_{3}$ (black), $20 \mathrm{MoO}_{3}-50 \mathrm{ZnO}-30 \mathrm{~B}_{2} \mathrm{O}_{3}(\mathrm{cross})$ and $30 \mathrm{MoO}_{3}-50 \mathrm{ZnO}-20 \mathrm{~B}_{2} \mathrm{O}_{3}$ (grey) glasses.

For the low boron content sample the relative number of 3 -fold coordinated boron atoms is significantly higher than that for the higher boron content samples, as it is seen in Figure 6/a and from the numerical values of $\mathrm{BO}_{3} /\left\{\mathrm{BO}_{3}+\mathrm{BO}_{4}\right\}$ and $\mathrm{BO}_{4} /\left\{\mathrm{BO}_{3}+\mathrm{BO}_{4}\right\}$ fractions (\%) (see Table 3). In consequence, the average $C N_{B-O}$ slightly increases with increasing $\mathrm{B}_{2} \mathrm{O}_{3}$. For the Mo-O and for $\mathrm{Zn}-\mathrm{O}$ coordination number distributions mainly 4-fold coordinated oxygen atoms are obtained, the number of different types of neighbors is $<5 \%$. Note, that the coordination number distribution pattern are significantly different: for Mo-O distribution: the number of 4-fold coordinated neighbors increases in the RMC simulation box due to the increasing $\mathrm{MoO}_{3}$ content, while for $\mathrm{Zn}-\mathrm{O}$ it is constant due to the constant $50 \mathrm{~mol} \%$ Zone content of the samples.

Table 3. Average coordination numbers, $C N_{i j}\left(\right.$ atom) and $\mathrm{BO}_{3}, \mathrm{BO}_{4} /\left\{\mathrm{BO}_{3}+\mathrm{BO}_{4}\right\}$ fraction (\%) as obtained from RMC modelling. The error is about $5 \%$ as estimated from the data analyses of different RMC runs.

\begin{tabular}{|c|c|c|c|c|c|}
\hline \multirow{3}{*}{ Sample } & \multirow{2}{*}{\multicolumn{2}{|c|}{ Fraction $(\%)$}} & \multicolumn{3}{|c|}{ Coordination numbers, $C N_{\mathrm{ij}}$ (atom) } \\
\hline & & & \multicolumn{3}{|c|}{ Atom pairs } \\
\hline & $\mathrm{BO}_{3}$ & $\mathrm{BO}_{4}$ & B-O & Mo-O & Zn-O \\
\hline $10 \mathrm{MoO}_{3}-50 \mathrm{ZnO}-40 \mathrm{~B}_{2} \mathrm{O}_{3}$ & 74 & 26 & 3.3 & 3.9 & 3.8 \\
\hline $20 \mathrm{MoO}_{3}-50 \mathrm{ZnO}-30 \mathrm{~B}_{2} \mathrm{O}_{3}$ & 83 & 17 & 3.2 & 3.9 & 3.9 \\
\hline $30 \mathrm{MoO}_{3}-50 \mathrm{ZnO}-20 \mathrm{~B}_{2} \mathrm{O}_{3}$ & 92 & 8 & 3.1 & 3.9 & 4.0 \\
\hline
\end{tabular}


The calculated average $C o_{m o-O}$ and $C o_{\text {nan-o }}$ are $\sim 4$ atoms, as shown in Table 3. It can be concluded that tetrahedral $\mathrm{MO}_{4}$ and $\mathrm{ZnO}_{4}$ units are formed, which is especially interesting for $\mathrm{Zn}-\mathrm{O}$ coordination.

The RMC modeling also provides information on the second coordination sphere. Significant atomic correlations have been established from the second neighbor distribution functions, as illustrated in Figure 7. The analyses of distances between metal-metal atoms are: Mo-Zn (2.90 $⿱$ ) , Zn-Zn (3.05 $\AA$ ), Mo-Mo (3.15 $\AA$ ), between boron-metal are: B-Zn (2.85 $\AA)$, B-Mo (3.10 $\AA)$ and B-B (2.60 $\AA)$ (see Table 2).

a)

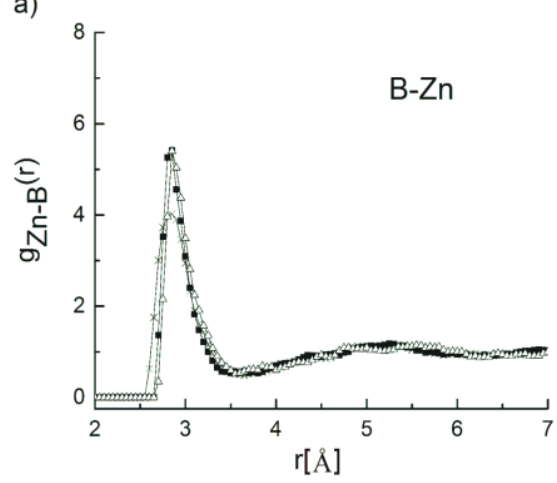

c)

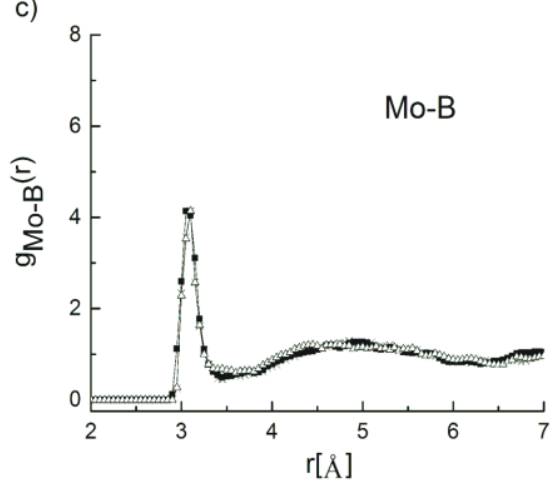

e)

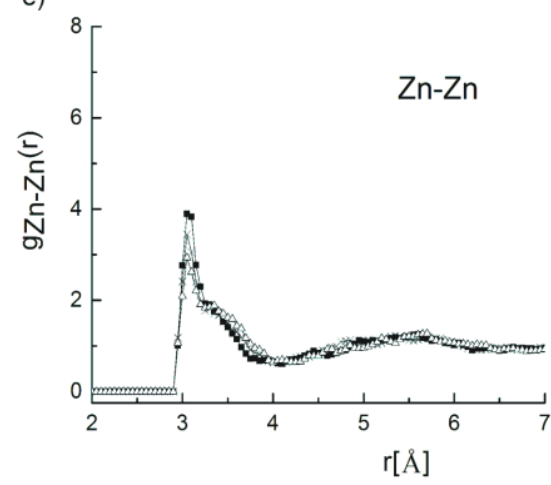

b)

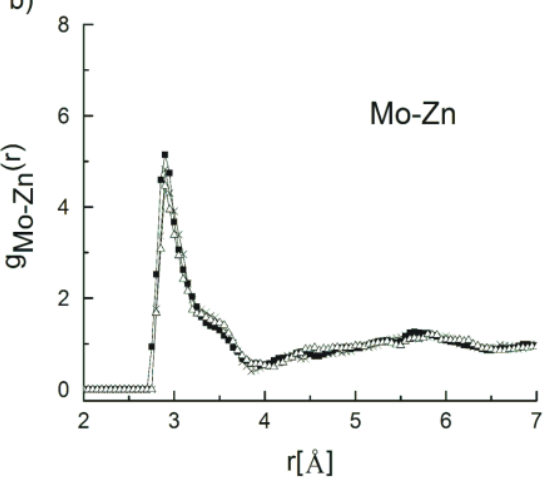

d)

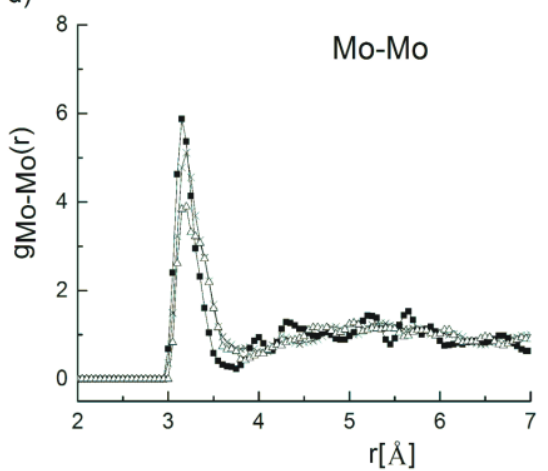

f)

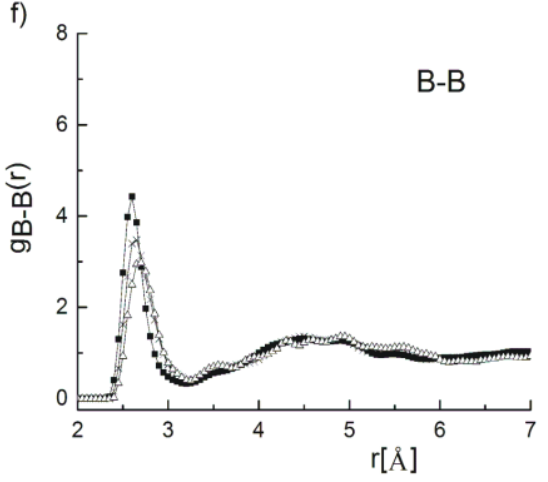

Figure 7. Second neighbour distribution functions for $10 \mathrm{MoO}_{3}-50 \mathrm{ZnO}-40 \mathrm{~B}_{2} \mathrm{O}_{3}$ (square), $20 \mathrm{MoO}_{3}-$ $50 \mathrm{ZnO}-30 \mathrm{~B}_{2} \mathrm{O}_{3}$ (cross) and $30 \mathrm{MoO}_{3}-50 \mathrm{ZnO}-20 \mathrm{~B}_{2} \mathrm{O}_{3}$ (triangle) glasses.

\section{Discussion}

We have established from the RMC modeling that the basic structural units are trigonal $\mathrm{BO}_{3}$ and tetrahedral $\mathrm{BO}_{4}, \mathrm{MoO}_{4}$ and $\mathrm{ZnO}_{4}$ groups, and a significant correlation exists between these units. Here we focus our interest on the analysis of bond-linkages forming the medium-range structure.

As far as, the network former groups are linked through $\mathrm{O}^{2-}$ ions, we have calculated the oxygen centered $\mathrm{O}-\mathrm{B}, \mathrm{O}-\mathrm{Mo}, \mathrm{O}-\mathrm{Zn}$ coordination number distributions. In the literature little interest has been 
directed to the examination of the oxygen neighborhood with respect to network formers, as far as we know, although this may be highly informative. The results are shown in Figure 8.
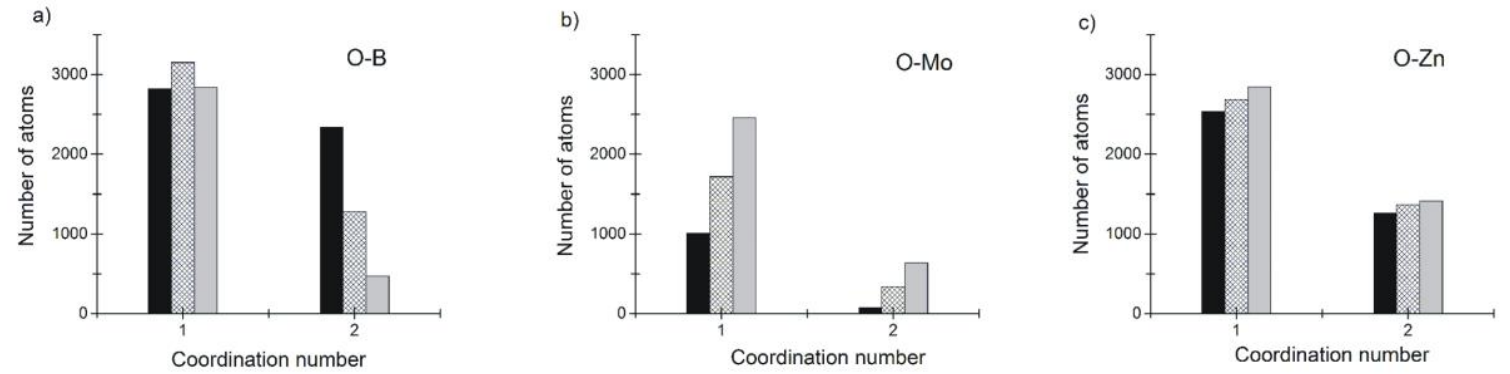

Figure 8. Oxygen centred coordination number distributions a) O-B, b) O-Mo, c) O-Zn where $10 \mathrm{MoO}_{3}-50 \mathrm{ZnO}-40 \mathrm{~B}_{2} \mathrm{O}_{3}$ (black), $20 \mathrm{MoO}_{3}-50 \mathrm{ZnO}-30 \mathrm{~B}_{2} \mathrm{O}_{3}$ (cross) and $30 \mathrm{MoO}_{3}-50 \mathrm{ZnO}-20 \mathrm{~B}_{2} \mathrm{O}_{3}$ (grey) glasses.

$\mathrm{O}^{-2}$ ions may be linked to 2 identical atoms, namely B-O-B, Mo-O-Mo, Zn-O-Zn or to 2 different types of atoms, namely B-O-Zn, B-O-Mo, Mo-O-Zn. We have calculated the relative number (fraction \%) of the two types of linkages, the results are tabulated in Table 4. The average O-B, O-Mo and $\mathrm{O}-\mathrm{Zn}$ coordination numbers are also included in Table 4.

Table 4. Average coordination numbers, $C N_{i j}$ (atom) and relative number (fraction \%) of $\mathrm{O}^{-2}$ ions linked to different neighbours, denoted by $\mathbf{1}$ or to identical neighbours, denoted by $\mathbf{2}$, as obtained from RMC modelling.

\begin{tabular}{|c|c|c|c|c|c|c|c|c|c|}
\hline \multirow{4}{*}{ Sample } & \multicolumn{3}{|c|}{ O-B } & \multicolumn{3}{|c|}{ O-Mo } & \multicolumn{3}{|c|}{ O-Zn } \\
\hline & \multicolumn{2}{|c|}{ Fraction (\%) } & \multirow[t]{3}{*}{$C N O-B$} & \multicolumn{2}{|c|}{ Fraction (\%) } & \multirow[t]{3}{*}{ CNo-Mo } & \multicolumn{2}{|c|}{ Fraction (\%) } & \multirow[t]{3}{*}{ CNo-Zn } \\
\hline & 1 & 2 & & 1 & 2 & & 1 & 2 & \\
\hline & $\begin{array}{c}\text { B-O- } \\
\text { Mo, Zn }\end{array}$ & $\begin{array}{c}\text { B-O- } \\
\text { B }\end{array}$ & & $\begin{array}{c}\text { Mo-O- } \\
\text { B,Zn }\end{array}$ & $\begin{array}{c}\text { Mo-O- } \\
\text { Мo }\end{array}$ & & $\begin{array}{l}\text { Zn-O- } \\
\text { B,Mo }\end{array}$ & $\begin{array}{c}\text { Zn-O- } \\
\text { Zn }\end{array}$ & \\
\hline $10 \mathrm{MoO}_{3}-50 \mathrm{ZnO}-40 \mathrm{~B}_{2} \mathrm{O}_{3}$ & 55 & 45 & 1.45 & 93 & 7 & 1.07 & 67 & 33 & 1.33 \\
\hline $20 \mathrm{MoO}_{3}-50 \mathrm{ZnO}-30 \mathrm{~B}_{2} \mathrm{O}_{3}$ & 71 & 29 & 1.29 & 84 & 16 & 1.16 & 66 & 34 & 1.34 \\
\hline $30 \mathrm{MoO}_{3}-50 \mathrm{ZnO}-20 \mathrm{~B}_{2} \mathrm{O}_{3}$ & 86 & 14 & 1.14 & 79 & 21 & 1.21 & 67 & 33 & 1.33 \\
\hline
\end{tabular}

We have found concentration dependence for O-B and O-Mo coordination distributions, while no change was established for $\mathrm{O}-\mathrm{Zn}$. The fraction of $\mathrm{O}^{-2}$ ions linked to $1 \mathrm{Zn}^{2+}$ cation is $67 \%$ ( $\mathrm{Zn}-\mathrm{O}$ $\mathrm{B}, \mathrm{Mo}$ ), while $33 \%$ is linked to $2 \mathrm{Zn}^{2+}$ (Zn-O-Zn). As far as, in all samples the $\mathrm{ZnO}$ concentration is 50 mol \%, whereas $\mathrm{MoO}_{3} / \mathrm{B}_{2} \mathrm{O}_{3}$ changes, we can conclude that the linkages of $\mathrm{ZnO}_{4}$ units do not have significant preference neither to boron nor to molybdenum. RMC analyses of the experimental data have shown that the $\mathrm{Zn}-\mathrm{O}$ bond length is $1.97 \AA$ for all types of linkages, namely for $\mathrm{Zn}-\mathrm{O}-\mathrm{Zn}, \mathrm{Zn}-\mathrm{O}-$ Mo or $\mathrm{Zn}-\mathrm{O}-\mathrm{B}$, independently from the type of linkages of the tetrahedral $\mathrm{ZnO}_{4}$ units. These results also support that $\mathrm{ZnO}$ exhibit network former property.

For O-Mo distribution we obtain, that for the lowest $\mathrm{MoO}_{3}$ content sample the fraction of Mo-O-B, $\mathrm{Zn}$ mixed linkages is $93 \%$, and Mo-O-Mo linkage is only $7 \%$. With the increase of molybdenum content the fraction of $\mathrm{MoO}_{4}-\mathrm{MoO}_{4}$ linkages increases to $21 \%$, while the mixed linkages decrease to $79 \%$. It can be concluded, that $\mathrm{MoO}_{4}$ units prefer to link to other type units. With increasing $\mathrm{MoO}_{3}$ concentration appears an excess of oxygen, which induces formation of Mo-O-Mo linkages and could appear a "molybdenum-oxygen" framework, typical $\mathrm{Mo}_{2} \mathrm{O}_{7}{ }^{2-}$ ditetrahedral groups. Our RMC calculations have shown that the Mo-O distances are the same for the $\mathrm{MoO}_{4}$ tetrahedral units and the $\mathrm{Mo}_{2} \mathrm{O}_{7}^{2-}$ ditetrahedral groups within limit of error, in good agreement with the results reported in ref. [34].

The interpretation of O-B coordination distribution is more complicated, as far as, both trigonal $\mathrm{BO}_{3}$ and tetrahedral $\mathrm{BO}_{4}$ groups are present. In the literature it is widely discussed that $\mathrm{BO}_{3}$ is usually 
linked in boroxol ring or in single triangle $\mathrm{BO}_{3}[13,38]$, while mixed $\mathrm{BO}_{3}$ and $\mathrm{BO}_{4}$ units form well defined and stable polyborate groupings, which also occur in borate crystals, i.e. (di)-triborate, metaborate, (di and tri)-pentaborate superstructural units [9-11]. Table 4 shows, that more than 50\% of boron atoms are linked to $\mathrm{MoO}_{4}$ or $\mathrm{ZnO}_{4}$ (O-B column 1), and concentration dependence can be observed. The number of B-O-B linkages (O-B column 2 ) significantly decreases from $45 \%$ to $14 \%$ with increasing $\mathrm{MoO}_{3} / \mathrm{B}_{2} \mathrm{O}_{3}$. This means, that the boron centered units prefer the linkage to $\mathrm{MoO}_{4}$ or $\mathrm{ZnO}_{4}$. The analysis of the results for $\mathrm{BO}_{3}$ and $\mathrm{BO}_{4}$ fraction (see Table 3) shows that the relative number of $\mathrm{BO}_{3}$ significantly increases from $74 \%$ up to $92 \%$ with increasing $\mathrm{MoO}_{3} / \mathrm{B}_{2} \mathrm{O}_{3}$. From these observations we may conclude that only small amount of boroxol ring is formed in the network structure (in that case B-O-B bond-linkages should be observed). We suppose that the network is formed by $\mathrm{BO}_{3}$ and $\mathrm{BO}_{4}$ organized into superstructure units, and partly by separated $\mathrm{BO}_{3}$ triangles. They are linked to $\mathrm{MoO}_{4}$ or $\mathrm{ZnO}_{4}$, forming in this manner mixed bond-linkages.

In some aspect, similarity may be found with our previous interpretation of the multi-component borosilicate glasses [39], where we have established mixed network structure including ${ }^{[3]} \mathrm{B}-\mathrm{O}^{-[4]} \mathrm{Si}$ and ${ }^{[4]} \mathrm{B}-\mathrm{O}^{-[4]} \mathrm{Si}$ chain segments. In the present system the oxygen centered coordination number distributions show that most of Mo atoms favor to be connected through an oxygen to $\mathrm{Zn}$ and $\mathrm{B}$ atoms, and the majority of the $\mathrm{Zn}$ atoms prefers to be linked to $\mathrm{B}$ or Mo atoms forming in this way ${ }^{[4]} \mathrm{Mo}-\mathrm{O}-{ }^{[3]} \mathrm{B},{ }^{[4]} \mathrm{Mo}-\mathrm{O}-{ }^{[4]} \mathrm{B},{ }^{[4]} \mathrm{Mo}-\mathrm{O}-{ }^{[4]} \mathrm{Zn},{ }^{[3]} \mathrm{B}-\mathrm{O}-{ }^{[4]} \mathrm{Zn}$, ${ }^{[4]} \mathrm{B}-\mathrm{O}-{ }^{[4]} \mathrm{Zn}$ linkages.

\section{Conclusions}

Neutron diffraction study has been performed on $\mathrm{xMoO}_{3}-50 \mathrm{ZnO}-(50-\mathrm{x}) \mathrm{B}_{2} \mathrm{O}_{3}, \mathrm{x}=10,20,30 \mathrm{~mol} \%$ glasses, and the experimental data were simulated by reverse Monte Carlo modeling. The first- and second neighbor correlation functions, atomic distances and coordination numbers have been revealed, not yet reported for this system. It was found, that the first neighbor distances do not depend on concentration within error of limit, the actual values are $r_{B-O}=1.38 \AA, r_{M o-O}=1.72 \AA$ and $r_{Z n-O}=1.97 \AA . \mathrm{ZnO}$ proved to be a network former, not a modifier as it is often reported in the literature for similar systems. From the analyses of the obtained structural parameters we have concluded that the glassy network is formed by trigonal $\mathrm{BO}_{3}$ and tetrahedral $\mathrm{BO}_{4}, \mathrm{MoO}_{4}, \mathrm{ZnO}_{4}$ groups. Concentration dependence was found for the $\mathrm{BO}_{4} / \mathrm{BO}_{3}$ fraction, it increases with increasing $\mathrm{B}_{2} \mathrm{O}_{3}$ content. We have concluded that only small amount of boroxol ring is present and it is supposed that the network is formed by organization of $\mathrm{BO}_{3}$ and $\mathrm{BO}_{4}$ groups into superstructure units, and partly by separated $\mathrm{BO}_{3}$ triangles. The $\mathrm{BO}_{3}$ and $\mathrm{BO}_{4}$ units are linked to $\mathrm{MoO}_{4}$ or $\mathrm{ZnO}_{4}$, forming mixed ${ }^{[4]} \mathrm{Mo}-\mathrm{O}_{-}{ }^{[3],[4]} \mathrm{B},{ }^{[4]} \mathrm{Mo}-$ $\mathrm{O}-{ }^{[4]} \mathrm{Zn},{ }^{[3],[4]} \mathrm{B}-\mathrm{O}-{ }^{[4]} \mathrm{Zn}$ bond-linkages. Significant medium-range order exists up to $\sim 7 \AA$.

Acknowledgement - The authors are grateful to Dr. L. Alexandrov for sample preparation and for useful discussions. One of the authors (M. F.) is thankful to Adrian Maraloiu and Andrei Kuncser instrument scientists for their helpful assistance at the TEM investigation (Core Project No. PN09450102) and to Tomaz Cendrak instrument scientist at the NMR Centre. The research was partly supported by EU-FP7 No.283883-NMI3, the Central European Research Infrastructure Consortium (CERIC-ERIC) and OTKA-109384 and to the bilateral cooperation of Hungarian-Bulgarian Academy of Sciences NKM-62/2014.

\section{References}

1. L. Aleksandrov, T. Komatsu, R. Iordanova and Y. Dimitriev, „Structure study of $\mathrm{MoO}_{3}-\mathrm{ZnO}-\mathrm{B}_{2} \mathrm{O}_{3}$ glasses by Raman spectroscopy and formation of $\alpha-\mathrm{ZnMoO}_{4}$ nanocrystals," Optical Materials 33 [6], 839-845 (2011).

2. L. Alexandrov, R. Iordanova, Y. Dimitriev, K. Hamda, J. Ide and M. Milanova, „Glass Formation in the $\mathrm{MoO}_{3}-\mathrm{La}_{2} \mathrm{O}_{3}-\mathrm{Nd}_{2} \mathrm{O}_{3}$ System," Advanced Materials Research 39-40 37-40 (2008).

3. L. Alexandrov, R. Iordanova and Y. Dimitriev, "Glass formation in the $\mathrm{MoO}_{3}-\mathrm{Nd}_{2} \mathrm{O}_{3}-\mathrm{La}_{2} \mathrm{O}_{3}-\mathrm{B}_{2} \mathrm{O}_{3}$," J. Non-Cryst. Solids 355 2023-2026 (2009). 
4. L. Alexandrov, R. Iordanova and Y. Dimitriev, „Glass formation in the $\mathrm{MoO}_{3}-\mathrm{La}_{2} \mathrm{O}_{3}-\mathrm{B}_{2} \mathrm{O}_{3}$ system,” Phys. Chem. Glasses: European J. Glass Sci. Technol. B. 48 [4] 242-245 (2007).

5. Y. Dimitriev, R. Iordanova, L. Aleksandrov and K. L. Kostov, „Boromolybdate glasses containing rare earth oxides," Phys. Chem. Glasses: European J. Glass Sci. Technol. B. 50 [3] 212-218 (2009).

6. Y. Dimitriev and R. Iordanova, „Non-traditional molybdate glasses,” Phys. Chem. Glasses: European J. Glass Sci. Technol. B. 50 [2] 123-132 (2009).

7. R. Iordanova, L. Aleksandrov, A. Bachvarova-Nedelcheva, M. Ataala and Y. Dimitriev, "Glass formation and structure of glasses in $\mathrm{B}_{2} \mathrm{O}_{3}-\mathrm{Bi}_{2} \mathrm{O}_{3}-\mathrm{MoO}_{3}$ system," J. Non-Cryst. Solids 357 2663-2668 (2011).

8. L. Aleksandrov, T. Komatsu, R. Iordanova and Y. Dimitriev, "Study of molybdenum coordination state and crystallization behavior in $\mathrm{MoO}_{3}-\mathrm{La}_{2} \mathrm{O}_{3}-\mathrm{B}_{2} \mathrm{O}_{3}$ glasses by Raman spectroscopy," Journal of Physics and Chemistry of Solids 72 263-268 (2011).

9. A. C. Wright, J. L. Shaw, R. N. Sinclair, N. M. Vedishcheva, B. A. Hakhmatkin and C. R. Scales, "The use of crystallographic data in interpreting the correlation function for complex glasses," J. NonCryst. Solids 345-346 24-33 (2004).

10. A. C. Wright, R. N. Sinclair, C. E. Stone and J. L. Shaw, "A neutron diffraction study of $2 \mathrm{M}_{2} \mathrm{O} .5 \mathrm{~B}_{2} \mathrm{O}_{3}(\mathrm{M}=\mathrm{Li}, \mathrm{Na}, \mathrm{K}, \mathrm{Rb}, \mathrm{Cs} \& \mathrm{Ag})$ and $2 \mathrm{MO}^{2} \mathrm{~B}_{2} \mathrm{O}_{3}(\mathrm{M}=\mathrm{Ca} \& \mathrm{Ba})$ glasses," Phys. Chem. Glasses Eur. J. Glass Sci. Technol. B 53 191-204 (2012).

11. N. Barrow, Superstructural units in lithium borate glasses, Department of Physics, University of Warwick, Coventry, CV4 7AL, 2006.

12. N. Ohtori, K. Takase, I. Akiyama, Y. Suzuki, K. Handa, I. Sakai, Y. Iwadate, T. Fukunaga and N. Umesaki, "Short-range structure of alkaline-earth borate glasses by pulsed neutron diffraction and molecular dynamics simulation," J. Non-Cryst. Solids 293-295 136-145 (2001).

13. M. Fábián, E. Sváb, Th. Proffen and E. Veress, "Neutron diffraction and reverse Monte Carlo modelling of $v-\mathrm{B}_{2} \mathrm{O}_{3}$ and $75 \mathrm{~B}_{2} \mathrm{O}_{3}-25 \mathrm{Na}_{2} \mathrm{O}$ glasses," J. Non-Cryst. Solids $356441-446$ (2010).

14. M. Fábián, E. Sváb and M. v. Zimmermann, „Structure study of new uranium loaded borosilicate glasses, “ J. Non-Cryst. Solids 380 71-77 (2013).

15. S. K. Lee, K. Mibe, Y. Fei, G. D. Cody and B. J. Mysen, "Structure of B2O3 Glass at High Pressure: A ${ }^{11}$ B Solid-State NMR Study," Physical Review Letters 94 165507(2005).

16. D. Lin-Shu and J. F. Stebbins, „Solid-state NMR study of metastable immiscibility in alkali borosilicate glasses," J. Non-Cryst. Solids 315 [3] 239-255 (2003).

17. O. Bouty, J. M. Delaye, B. Beuneu and T. Charpentier, „Modelling borosilicate glasses of nuclear interest with the help of RMC, WAXS, neutron diffraction and ${ }^{11}$ B NMR," J. Non-Cryst. Solids 401 27-31 (2014).

18. M. Fabian, E. Svab and K. Krezhov, „Neutron diffraction and RMC modeling of new amorpous molybdate system," Journal of Physics:Conference Series 558012017 (2014).

19. G. Calas, M. Le Grand, L. Galoisy and D. Ghaleb, „Structural role of molybdenum in nuclear glasses: an EXAFS study," Journal of Nuclear Materials 322 [1] 15-20 (2003).

20. J. Subcik, L. Koudelka, P. Mosner, L. Montagne, B. Revel and I. Gregora, „Structure and properties of $\mathrm{MoO}_{3}$-containing zinc borophosphate glasses," J. Non-Cryst. Solids 355 [16-17] 970975 (2005).

21. U. Hoppe, G. Walter, R. Kranold, D. Stachel and A. Barz, „The dependence of structural peculiarities in binary phosphate glasses on their network modifier content," J. Non-Cryst. Solids 192193 28-31 (1995).

22. U. Hoppe, G. Walter, D. Ilieva, G. Carl and J. Neuefeind, „Me-O coordination numbers in Ga and $\mathrm{Zn}$ phosphate glasses from meta- to pyrophosphate compositions-a high-energy X-ray diffraction study,"http://hasyweb.desy.de/science/annual_reports/2001_report/part1/contrib/44/4829 (2001).

23. D. A. McKeown, I. S. Muller, A. C. Buechele and I. L. Pegg, „Local environment of Zn in zirconium borosilicate glasses determined by X-ray absorption spectroscopy," J. Non-Cryst. Solids 
261 [1-3] 155-162 (2000).

24. D. Saritha, Y. Markandeya, M. Salagram, M. Vithal, A. K. Singh and G. Bhikshamaiah, „Effect of $\mathrm{Bi}_{2} \mathrm{O}_{3}$ on physical, optical and structural studies of $\mathrm{ZnO}-\mathrm{Bi}_{2} \mathrm{O}_{3}-\mathrm{B}_{2} \mathrm{O}_{3}$ glasses," J. Non-Cryst. Solids 54 5573-5579 (2008).

25. S. Rada, P. Pascuta, L. Rus, M. Rada and E. Culea, „Spectroscopic properties and ab initio calculations on the structure of erbium-zinc-borate glasses and glass ceramics," J. Non-Cryst. Solids 358 30-35 (2012).

26. R. L. McGreevy and L. Pusztai, "Reverse Monte Carlo Simulation: A New Technique for the Determination of Disordered Structures," Mol. Simul. 1 359-367 (1988).

27. National Institute of Materials Physics, Bucharest, Romania, http://lab50.infim.ro/tem.htm\#

28. Slovenian NMR Centre, http://www.nmr.ki.si/600_magnet.html

29. E. Sváb, Gy. Mészáros and F. Deák, „Neutron powder diffractometer at the Budapest research reactor," Materials Science Forum 228 247-252(1996); http://www.bnc.hu/

30. J. P. Ambroise, M. C. Bellissent-Funel and R. Rellissent, „Neutron scattering determination of local order in amorphous and liquid systems using a position sensitive detector," Rev. Phys. Appl. 19 731-734 (1984); http://www-llb.cea.fr/en/

31. A.C. Hannon, „ISIS Disordered Materials Database,”

http://www.isis.stfc.ac.uk/groups/disordered-materials/database/ (2006).

32. Reverse Monte Carlo homepage, http://www.szfki.hu/ nphys/rmc++/opening.html

33. L. Alexandrov, private communication.

34. M. Rada, S. Rada, P. Pascuta and E Culea, "Structural properties of molybdenum-lead-borate glasses," Spectrochimia Acta Part A 77 832-837 (2010).

35. D. Caurent, O. Majerus, E. Fadel, A. Quintas, C. Gervais, T. Charpentier and J. Neuville, "Structural investigations of borosilicate glasses containing $\mathrm{MoO}_{3}$ by MAS NMR and Raman spectroscopies," Journal of Nuclear Materials 396 94-101 (2010).

36. K. Suzuya, K. Itoh, A. Kajinami and C. K. Loong, "The structure of binary zinc phospate glasses," J. Non-Cryst. Solids 345-346 80-87 (2004).

37. G. Calas, L. Cormier, L. Galoisy and P. Jollivet, "Structure-property relationships in multicomponent oxide glasses," Comptes Rendus Chimie 5 831-843 (2002).

38. C. Joo, U. Werner-Zwanziger and J. W. Zwanziger, „The ring structure of boron trioxide glass, “ $J$. Non-Cryst. Solids 261 282-286 (2000).

39. M. Fabian, E. Svab, Th. Proffen and E. Veress, "Structure study of multi-component borosilicate glasses from high-Q neutron diffraction measurement and RMC modeling," J. Non-Cryst. Solids 354 3299-3307 (2008). 